\title{
Moisture performance of a new thermal insulation composite for interior application
}

\author{
Carsten Rode ${ }^{1, *}$, Naja Kastrup Friis ${ }^{1}$, Christian Pedersen ${ }^{1}$, Nickolaj Feldt Jensen $^{1}$ \\ ${ }^{1}$ Technical University of Denmark, Department of Civil Engineering, 2800 Kgs. Lyngby, Denmark
}

\begin{abstract}
The paper introduces prototypes of a new composite insulation product for interior application. The product consists of a standard mineral fibre insulation batt, which is wrapped in a combination of a thin fabric of moisture absorbing, capillary active material and vapour retarding membranes. The insulation composite has been tested with small samples in a laboratory setup and in an outdoor field test on a full-scale brick wall, and has so far shown promising results in comparison with other products. The paper describes the new insulation composite and the initial moisture tests that have been made with its constituents as well as results from the laboratory and field tests of its ability to prevent moisture accumulation.
\end{abstract}

\section{Introduction}

In order to preserve the exterior aesthetics of an existing outer wall, thermal insulation is often applied on the inside of walls of historic buildings when they are energy renovated, despite of the fact that in cold climates, interior insulation incurs a risk of moisture accumulation at the interface between the original wall and the installed insulation. For this reason, a lot of research has been invested in recent years in the topic of interior insulation of historical buildings, e.g. the European project RIBuild [1], which has dealt exactly with renovation by interior insulation of building from before 1945. A recent $\mathrm{PhD}$ study [2] investigated interior insulated solid brick walls in a setup where 24 similar walls with different interior insulation systems were tested side by side -16 of them facing south-west and 8 facing north-east.

The insulation system tested can be seen as an alternative to the mineral wool based system with interior polyethylene vapour retarder, which has traditionally been used in Denmark. The traditional system only works well if very good care is paid to ensure a tight vapour retarder, which may be difficult to realise in practice. In some cases, a tight vapour retarder is exactly not desired, since it might prevent moisture to escape, e.g. if it comes from the outside after rain and solar driven inward drive. Instead, diffusion open systems could be advocated for, as they permit too high moisture contents in the insulation systems to escape towards the interior, when conditions are amenable. However, in a Nordic climate the caveat is that it incurs a risk of significant moisture accumulation at the interface between the interior insulation and the original, solid outer wall, which is now colder.
Some insulation systems have been developed, or in some cases been revitalized from the past, that facilitate a movement of moisture from the cold side of the insulation towards the warm indoor side. Such systems comprise very lightweight aerated concrete, calcium silicate, and cellular foam insulation system such as polyurethane or phenolic insulation. The foam insulation systems may be manufactured with narrow channels of calcium silicate that permit suction of water back from the cold to the warm side of the insulation board, such as iQ-Therm [3]. As demonstrated for instance in [2], even the diffusion open systems with possible capillary active properties cannot ensure a moisture safe solution. Their good performance depends of course on the severity of the indoor and outdoor boundary conditions, but can also be enhanced by the use of hydrofobing agents on the outdoor façade. Moisture sensible wooden elements in the walls, such as beams and laths, may be protected by strategically positioned thermal bridges. However, this paper will not study the use of hydrofobing agent or thermal bridges any further.

A somewhat related problem exists for insulation of cold pipe systems where the continuous keeping of a cold temperature and vapour tight surface at the pipe leads to the risk of moisture built up over time in the coldest inner part of the insulation, when the dew-point of the ambient is above the pipe temperature. The traditional solution has been to use rather vapour tight, closed foam insulation, but practice shows that it only delays, but do not eliminate the problem. Korsgaard invented the so-called HygroWick system [4] to alleviate such problems. A nonwoven fabric or glass-fibre felt with capabilities to function as a wick is wound around the cold pipe, see

\footnotetext{
*Corresponding author: car@byg.dtu.dk
} 
Fig. 1, left. After making a turn around the pipe, the fabric is led through the slit of the pipe-section, which can be made of a diffusion open material such as mineral wool. The outside of the pipe section has an outer jacket of vapour tight material, and a small piece of the fabric should be led out of the pipe section to the ambient, where it can be attached to the outer surface of the vapour tight jacket. The jacket keeps moisture ingress into the system slow, but nevertheless, when moisture accumulates on the pipe, it will be absorbed by the fabric so it functions as a wick that transports the moisture to the outside of the pipe. The principle has proven functional and is today a commercial system [5]. There are variations of the system, which keep the wick away from frost if the pipe temperature is below $0^{\circ} \mathrm{C}$. It is also possible to put an extra jacket on the complete outside of the system to make it suitable for used in rooms where hygienic requirements do not permit the potentially wet fabric to be exposed. These variations of the system are functional, too.

Inspired by the situation of interior insulation of outer wall systems, and the principle of HygroWick, we have developed a system to keep interior insulation batts dry by using a wick that absorbs moisture from where it would potentially condensate and transports it back to the indoor environment. This paper describes the system including both laboratory experiments and a field test in which prototypes of the system have been tested. Both types of experiments are compared with two known interior systems: Monolithic calcium silicate boards and the system marketed as iQ-Therm [3]. For reference, the system described here in this paper is called "HygInsu". The laboratory test have been described in [6], and this work is explained in summary here in the paper.

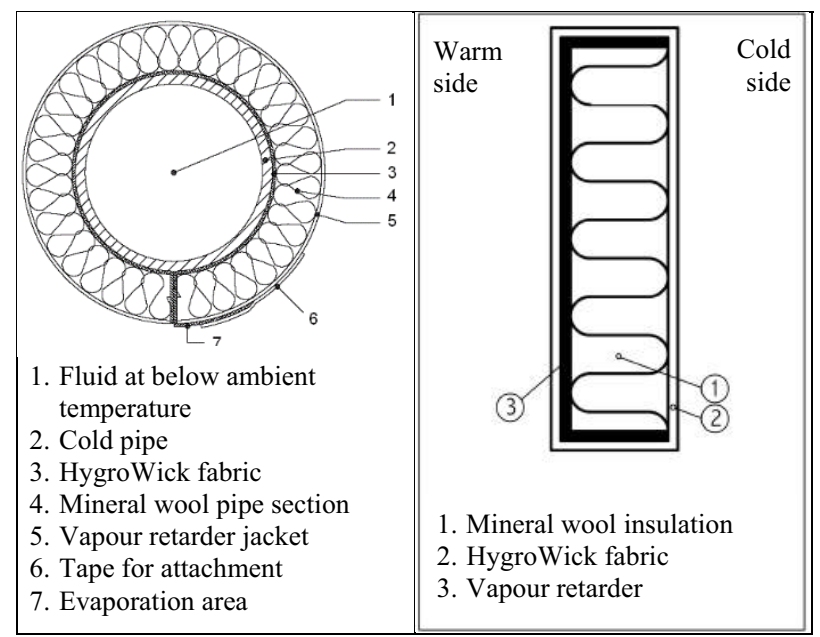

Fig. 1 Sketch of the HygroWick system used on cold piping (left), and the principle of the HygInsu interior wall insulation system (right).

\section{Description of Hyglnsu}

HygInsu is a composite material consisting of an effective insulating stone wool product protected by a diffusiontight vapour barrier wrapped with a moisture-transporting fabric. Fig. 1, right, shows the composition of the HygInsu system. When the system is installed on a wall, the insulation plane is broken at every batt, thus creating slits that allow the wick to pass through. The capillary absorbing wick is wound around the batts in a single continuous layer so that moisture transport will not get interrupted. The wick is routed all the way around the insulation batt from the side that will face the cold, solid wall to the side that will be behind the interior wall cladding, which will typically be gypsum board. A vapour retarder is placed between the wick and the insulation on the warm side of the insulation, and down the sides of the insulation batt, and has a diffusion resistance $\mathrm{Z}=200 \mathrm{GPa} \cdot \mathrm{s} \cdot \mathrm{m}^{2} / \mathrm{kg}\left(s_{d}=36 \mathrm{~m}\right)$. To prevent leaks, the vapour retarder consists of a large rectangular piece where the corner joints are folded in and taped.

\section{Laboratory tests}

\subsection{Purpose}

The purpose of the experiments was to compare the efficiency of the three insulation systems: calcium silicate, iQ-Therm, and HygInsu when mounted as interior insulation on a cold brick wall. The experimental set-up was to determine the distribution of water content, temperature, relative humidity and water vapour pressure in the samples over time. This was done to assess whether the samples in equilibrium were able to actively remove moisture as it accumulated.

\subsection{Method}

The cold brick wall, on which the samples were placed, was imitated by two kitchen refrigerators located in a large climate chamber that established the indoor ambient conditions. The drawing of an exploded view and a picture of the front elevation of the setup are shown in Fig. 2 . The refrigerator doors were replaced with sheet metal plate, which on the outside was insulated with foam rubber insulation. Square holes were cut in the rubber insulation in which the interior insulation samples would fit. Thus, the temperature difference over the samples and the relative humidity, $\mathrm{RH}$, in the room on the warm side were kept constant throughout the experimental period. The air in the climate chamber was kept constant at $23{ }^{\circ} \mathrm{C}$ and the humidity at $65 \% \mathrm{RH}$. The refrigerators were kept a temperature of about $4{ }^{\circ} \mathrm{C}$, so that there would be a cold surface with a temperature below the ambient dew point. The samples of the three selected insulation materials were placed in plexiglass boxes with interior dimensions of $20 \mathrm{~cm} \times 20 \mathrm{~cm}$. The boxes were made of $5 \mathrm{~mm}$ plexiglass and had an inside depth of $10 \mathrm{~cm}$. The boxes allowed that the samples could easily be removed from the cold plate for weighing at regular intervals, so changes in total water content could be followed.

The foam rubber insulation gave a spacing of $6 \mathrm{~cm}$, between the plexiglass boxes. The foam rubber has a high water vapour resistance factor $(\mu \geq 10,000)$ and good insulation properties $(\lambda \leq 0.033 \mathrm{~W} /(\mathrm{m} \cdot \mathrm{K}))$, so the heat flow through the samples would be practically onedimensional perpendicular to the insulation plane.

A fan was installed in each refrigerator to provide a uniform temperature distribution over the cold sheet metal plate. This, unfortunately, was not achieved as effectively 
as expected, resulting in the temperature varying from 4.5 to $7{ }^{\circ} \mathrm{C}$. The surface was coldest $100 \mathrm{~cm}$ from the ground and warmest at the bottom. The temperature of the two refrigerators was calibrated to be reasonably equal, but also this was not perfectly achieved, which could have some consequences on the comparability of the results. Furthermore, the plexiglass boxes constituted 3-dimensional thermal bridges around the insulation samples, which there could not be compensated for.
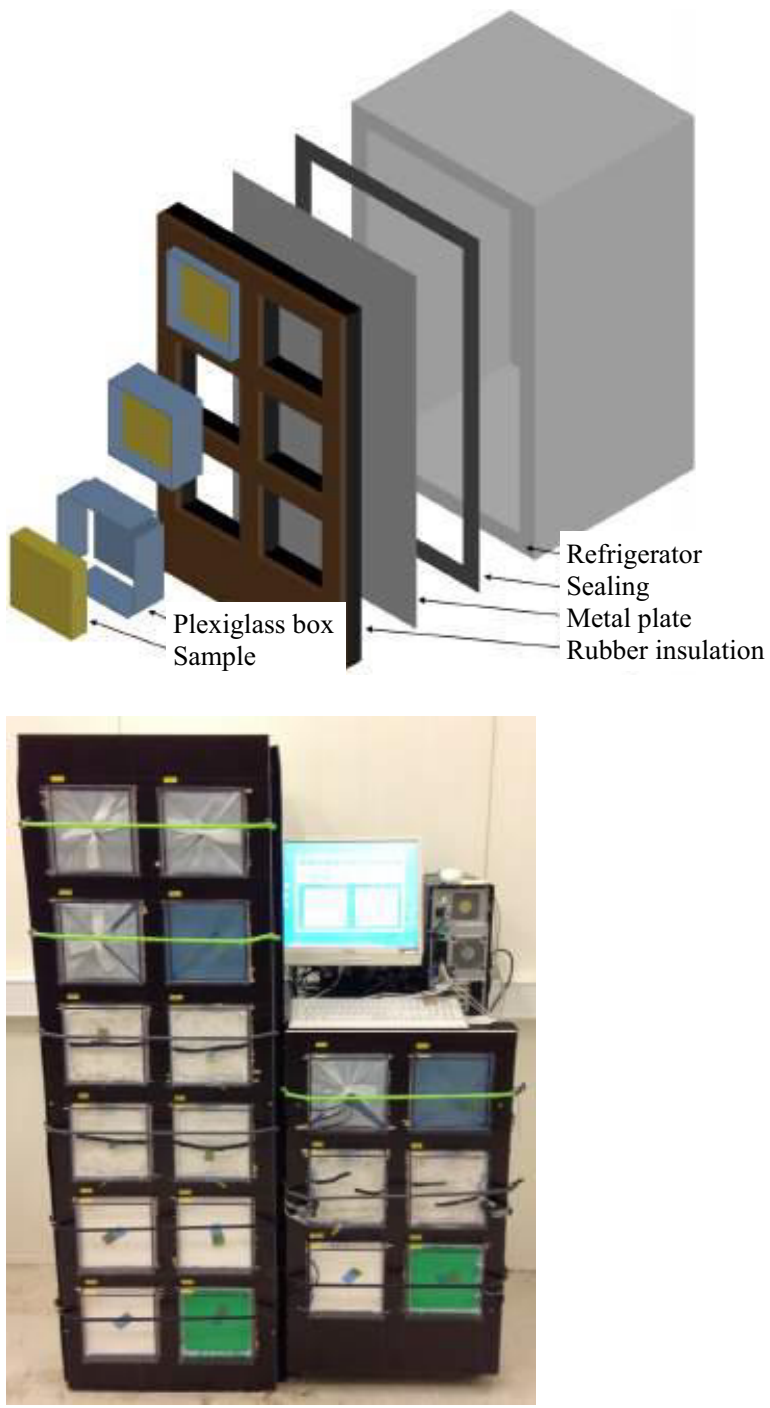

Fig. 2 Exploded view and picture of test setup for refrigerator tests.

\subsubsection{Samples}

The two refrigerators had each their function in the experiment. Four samples of each insulation system were placed on the largest of the refrigerators. These 12 samples were meant to be weighed. Two other samples of each material were put on the smallest of the refrigerators. These 6 samples were not weighed because they were equipped with wired moisture and temperature sensors and should be left undisturbed during the course of the measurements. Table 1 gives an overview of the 18 sample types and their location. The sample names are marked in bold and will be referred to later. All samples were constructed according to the recommendations of the manufacturers with a material thickness of $50 \mathrm{~mm}$ plus the recommended amounts of mortar and cladding. Neither of the samples had a wall cover or surface treatment (such as gypsum board and paint) on the surface that faced the climate chamber. 3 Sensirion SHT75 sensors that measure temperature and humidity were used in each of the wired samples. The sensors were placed at depths 11, 25 and $39 \mathrm{~mm}$ from the front of the insulation samples, and measurements took place at staggered positions horizontally at the centre of each sample and vertically at positions 50,100 and $150 \mathrm{~mm}$ from the side. Cable holes were drilled so the sensors and their cabling did not disturb each other.

Table 1 Overview of the 18 samples and their naming.

\begin{tabular}{|c|c|c|c|}
\hline 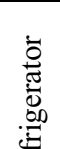 & $\begin{array}{l}\text { KA-1 } \\
\text { Calc. silicate } \\
\text { Sealed } \\
\text { With sensors }\end{array}$ & $\begin{array}{l}\text { IQ-1 } \\
\text { iQ-Therm } \\
\text { Sealed } \\
\text { With sensors }\end{array}$ & $\begin{array}{l}\text { HY-1 } \\
\text { HygInsu } \\
\text { Sealed } \\
\text { With sensors }\end{array}$ \\
\hline 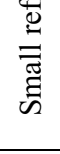 & $\begin{array}{l}\text { KA-2 } \\
\text { Calc. silicate } \\
\text { Open } \\
\text { With sensors }\end{array}$ & $\begin{array}{l}\text { IQ-2 } \\
\text { iQ-Therm } \\
\text { Open } \\
\text { With sensors }\end{array}$ & $\begin{array}{l}\text { HY-2 } \\
\text { HygInsu } \\
\text { Open } \\
\text { With sensors }\end{array}$ \\
\hline \multirow{4}{*}{ 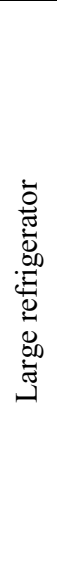 } & $\begin{array}{l}\text { KA-3 } \\
\text { Calc. silicate } \\
\text { Open } \\
\text { Weighted }\end{array}$ & $\begin{array}{l}\text { IQ-3 } \\
\text { iQ-Therm } \\
\text { Open } \\
\text { Weighted }\end{array}$ & $\begin{array}{l}\text { HY-3 } \\
\text { HygInsu } \\
\text { Open } \\
\text { Weighted }\end{array}$ \\
\hline & $\begin{array}{l}\text { KA-4 } \\
\text { Calc. silicate } \\
\text { Open } \\
\text { Weighted }\end{array}$ & $\begin{array}{l}\text { IQ-4 } \\
\text { iQ-Therm } \\
\text { Open } \\
\text { Weighted }\end{array}$ & $\begin{array}{l}\text { HY-4 } \\
\text { HygInsu } \\
\text { Open } \\
\text { Weighted }\end{array}$ \\
\hline & $\begin{array}{l}\text { KA-5 } \\
\text { Calc. silicate } \\
\text { Open } \\
\text { Weighted }\end{array}$ & $\begin{array}{l}\text { IQ-5 } \\
\text { iQ-Therm } \\
\text { Open } \\
\text { Weighted }\end{array}$ & $\begin{array}{l}\text { HY-5 } \\
\text { HygInsu } \\
\text { Open } \\
\text { Weighted }\end{array}$ \\
\hline & $\begin{array}{l}\text { KA-6 } \\
\text { Calc. silicate } \\
\text { Sealed } \\
\text { Weighted } \\
\end{array}$ & $\begin{array}{l}\text { IQ-6 } \\
\text { iQ-Therm } \\
\text { Sealed } \\
\text { Weighted }\end{array}$ & $\begin{array}{l}\text { HY-6 } \\
\text { HygInsu } \\
\text { Sealed } \\
\text { Weighted }\end{array}$ \\
\hline
\end{tabular}

As can be seen in Table 1, six of the samples are marked as being sealed, rather than open. This means that the moisture transport in and out the samples has been prevented by sealing. The sealed samples were used as references to see how the materials would behave if they could not actively remove the moisture.

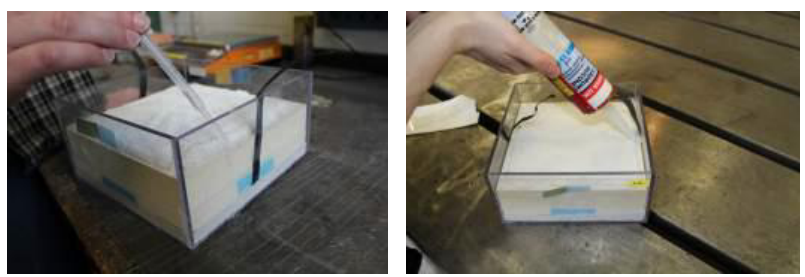

Fig. 3 A test box is wetted before start of the experiment and edges are sealed with silicone caulking.

Upon starting the experiment, some of the samples were wetted with water to kick-start the situation of a wet wall and see how this moisture would move. The amount of water added was equal to $80 \%$ of the water needed to saturate each material. Simulations in Delphin defined the saturation level. Thus, the calcium silicate wall samples KA-3, KA-4 and KA-5 were wetted with $72 \mathrm{~g}$ of water injected with a syringe, see Fig. 3, left. $50 \mathrm{~g}$ was added to 
the iQ-Therm wall samples IQ-3, IQ-4, IQ-5 and IQ-6, and $10 \mathrm{~g}$ was added to the HygInsu wall samples HY-3, HY-4 and HY-5. The duration of the measuring period was 116 days.

\subsection{Result and Analysis}

\subsubsection{Weighing results}

Fig. 4 shows all the weighing results for the three materials. Each curve refers to one of the samples described in Table 1. The data points illustrated with squares ( $\mathbf{\square})$ are for calcium silicate, where open samples are red. Diamonds ( $\downarrow)$ indicate the iQTherm results, and all the open samples are green. The results of the HygInsu samples are illustrated with circles $(\bullet)$ and the open samples have blue colours. Sealed samples are all black, no matter the insulation type. The weight gain is the difference between the measured weight and the initial weight.

\section{Calcium silicate}

As shown in

Fig. 4, the sealed calcium silicate sample does not gain weight at all because of its diffusion-tight paint. However, the open samples quickly gain weight, and after 10 weeks there is a maximum increase of 97 grams. After this peak, the weight change becomes more subtle, indicating that an equilibrium with the humidity of the ambient climate chamber has been attained. Common for all the initially soaked samples is that they lose much of the liquid added at the start of the experiment.

\section{$i Q$-Therm}

The first thing to note when considering the weighing results for iQ-Therm in Fig. 4 is that the weight gain is much lower than that of calcium silicate. This is caused by the calcium silicate being very hydrophilic, while the polyurethane core of $\mathrm{iQ}-$ Therm is water resistant with a closed pore system, meaning that the water is located primarily in the adhesive mortar near the cold surface. The graphs also show that all four samples have had the same constant weight gain since week 2 without signs of change. The last measurement is therefore also the highest, which means that there is no indication that the iQ-Therm tests have come in equilibrium with the indoor climate.

\section{HygInsu}

Due to the diffusion-tight vapour barrier that closes tightly around the mineral wool, the samples do not gain much in weight. For this reason, it would take long time before the wick would become wet enough to make the liquid transporting properties of HygInsu influential. To determine whether the HygInsu samples have a liquid moisture transporting property, the samples HY-5 and HY-4 were therefore wetted with some extra 20 grams of liquid during the experimental period. The water was supplied by means of a thin syringe and the hole in the vapour barrier subsequently sealed with tape. The 20 grams of water was supplied at a depth of $2.5 \mathrm{~cm}$ in the middle of the sample, but as shown in Fig. 4, it was removed with approximately one month when it got in contact with the HygroWick. By capillary action, the wick has led the moisture to the warm surface of the assembly from where it could evaporate towards the climate chamber. The result shows that HygInsu has an effective property for draining, which means that the assembly quickly attains a dry situation.

\subsubsection{Measurements from sensors}

Measurements were taken over a period of 112 days. For each material type, a first graph presents the development over time. The subsequent two smaller graphs show the moisture distributions within the samples at the end of the experimental period for the open and sealed experiments, respectively.

\section{Calcium silicate}

The measurements for KA-1 $(11 \mathrm{~mm})$ show that the relative humidity decreases during the first few weeks, while measurements for KA-1 $(39 \mathrm{~mm})$ increase. This shows that moisture accumulates where it is coldest and the water evaporates from the free surface to the ambient climate chamber. The results of the middle sensor in the open sample KA-1 (25 mm) show that after it has dropped in the first few days, it begins to rise and after two months it is at the same level like the rear sensor. This means that the condensation on the cold side has gradually spread further towards the warm side until it finally reached the sensor in the centre of the sample. The striking increase in relative humidity also corresponds to the large weight gain, which was seen in Fig. 4.

The measurements for the sealed sample KA-2 show almost as high relative humidity as the open. The reason could be due to water that has penetrated through the drilled holes in the side of the sample through which the sensor wires were led.

\section{iQ-Therm}

The open iQ-Therm sample (IQ-1) becomes more water filled than the sealed (IQ-2), especially in the two measuring points closest to the cold surface. This can be seen in Fig. 6 where the points for the relative humidity graph at a distance of $2.5 \mathrm{~cm}$ and $3.9 \mathrm{~cm}$ from the inner surface as well is higher.

The graph of the vapour pressure for IQ-1 makes an unnatural kink in Fig. 6, lower left. This is because of the low values in relative humidity measured in IQ-1 (11 $\mathrm{mm})$. Since the sensors only measure relative humidity and temperature, the vapour pressure is determined from $p=\varphi \cdot p_{s}$. The relative humidity at this point may be a result of the position of a sensor close to the capillary active channels.

\section{HygInsu}

There is a clear linear correspondence between the relative humidity and all of the three points in the mineral wool. This linearity is due to the fact that the material is homogeneous and unlike the other materials, the mineral wool has no capillary active or moisture absorbing properties. Therefore, there is no gradient in vapour 
pressure, and almost no change over time and no fluid front. Naturally, the relative humidity is highest near the cold surface.

The sealed sample should contain more moisture as it has no possibility to actively drain it, but this is not immediately apparent from these results. A probable reason could be that the liquid will be localized in a thin layer at the cold surface rather than within the mineral wool, and thus will not influence even the coldest sensor.

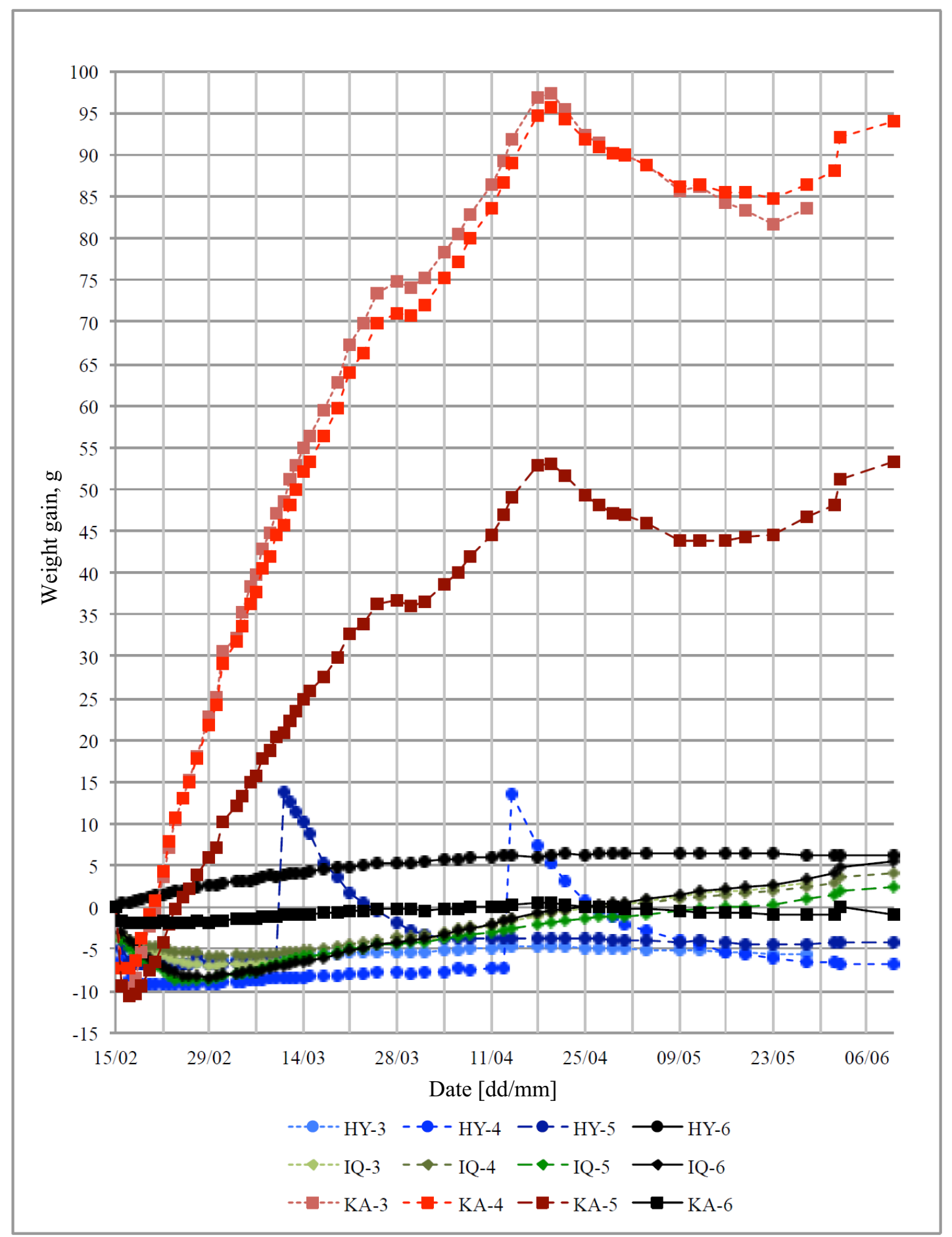

Fig. 4 Results from weighing of all samples from the large refrigerator.

\section{Field test}

\subsection{Description of the set-up}

A field test of a full-scale wall with HygInsu as interior insulation was carried out in an outdoor field test site of the Technical University of Denmark, $15 \mathrm{~km}$ north of Copenhagen city centre. The facility was comprised of two 40 " reefer containers that were positioned on the test site such that one of the long-sided wall surfaces faced north-east (and the opposite side faced south-west), and $1 \mathrm{~m}$ wide $\times 2 \mathrm{~m}$ tall openings were cut in the insulated steel walls in which some solid $1 \frac{1 / 2}{2}$ stone $(34.8 \mathrm{~cm})$ walls 
were bricked up. Each façade made room for 8 such wall mock-ups. See the exterior set-up on Fig. 8.

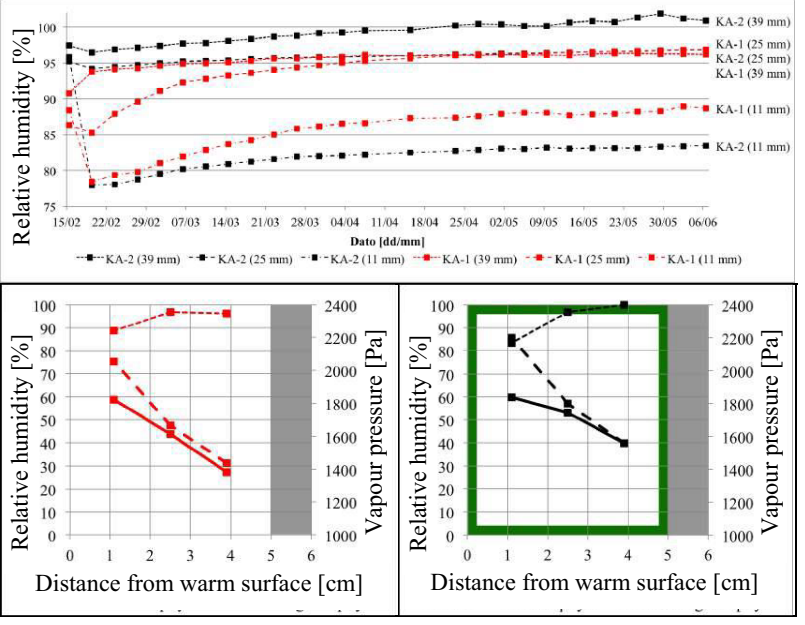

Fig. 5 Sensor results of the evolution and distribution of moisture content in calcium silicate. The lower graphs show moisture distributions after 112 days with relative humidity $(\cdots \cdots)$, vapour pressure $(-)$, and saturation vapour pressure (-----). Lower graphs are for the open specimen on the left and sealed specimen on the right.

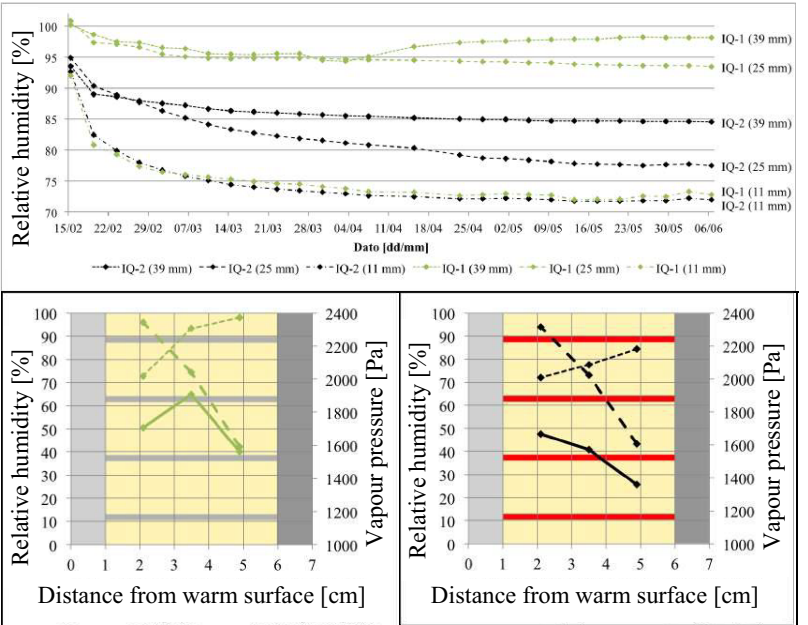

Fig. 6. Sensor results of the evolution and distribution of moisture content in iQ-Therm. Horizontal gray and red lines merely symbolize the calciumsilicate channels that pentrate the material, and are not to be seen as indicators of particular humidity values. Significance of line types like in Fig. 5.

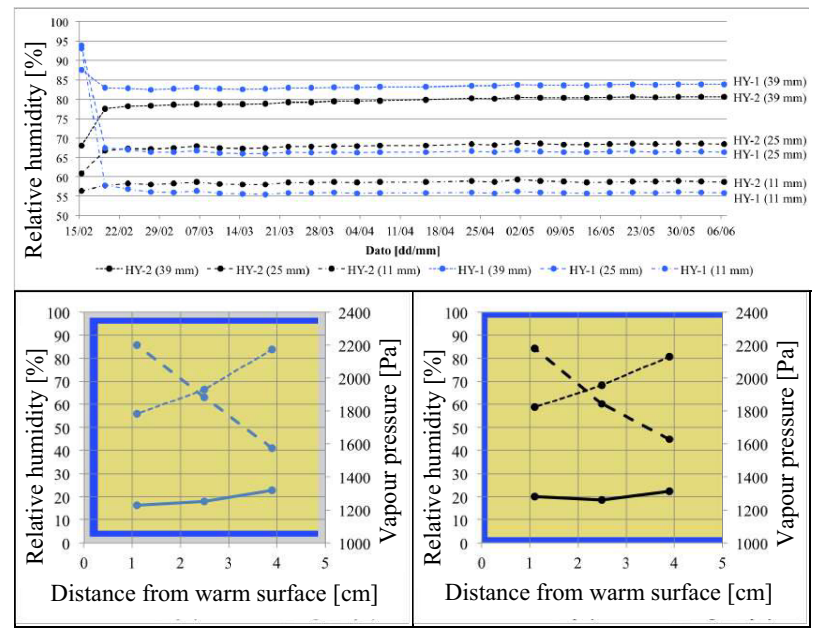

Fig. 7. Sensor results of the evolution and distribution of moisture content in HygInsu. Significance of line types like in Fig. 5.

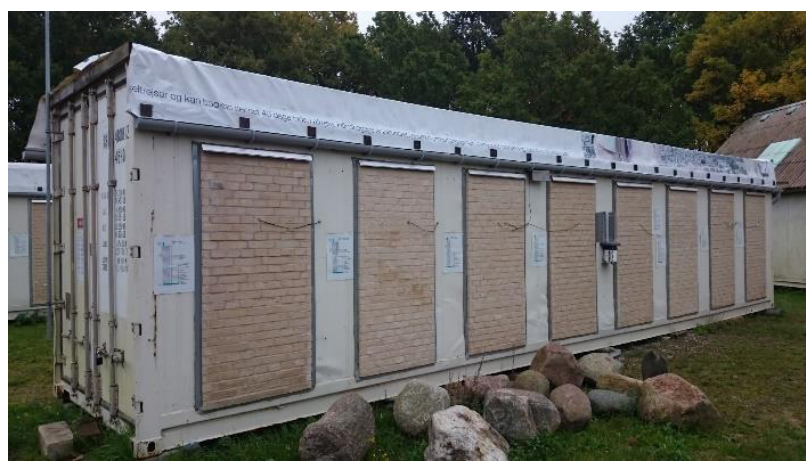

Fig. 8. South-west façade of reefer container used as facility for tests of hygrothermal conditions in interior insulated masonry walls.

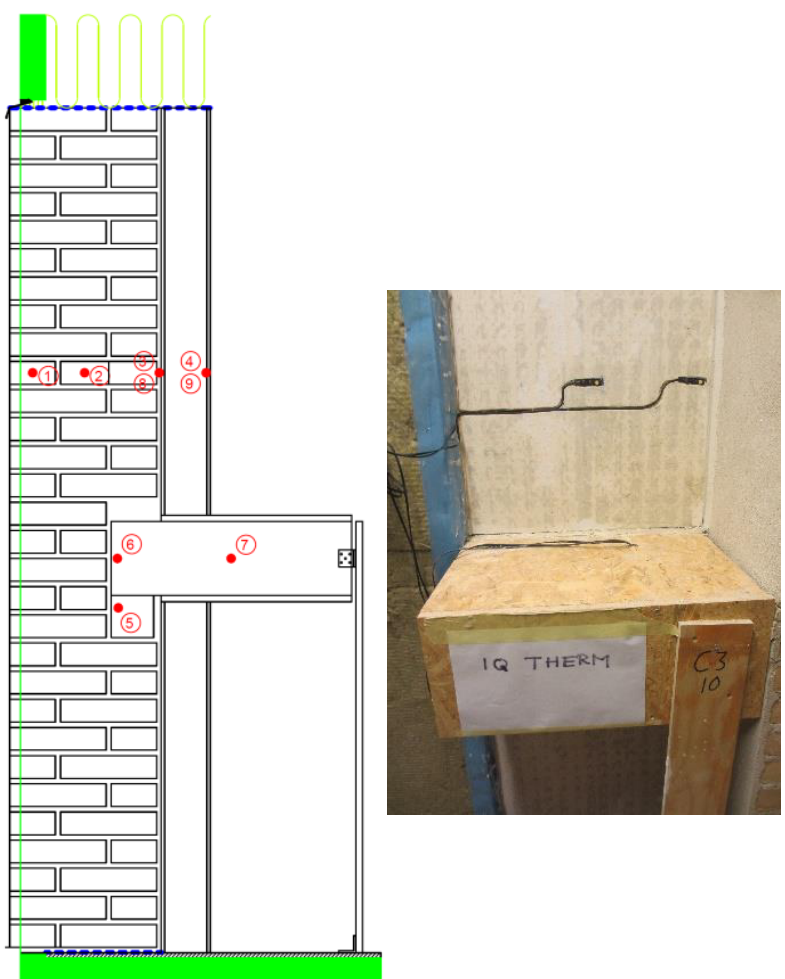

Fig. 9. Vertical cross-section of wall with interior insulation and location of sensors. Measuring positions 8 and 9 are duplicates of positions 3 and 4, but are placed at the separation wall, which can be seen on the right-hand side of the photo. The photo shows the wall with iQ-Therm insulation in place before mounting the interior gypsum wall cladding.

The masonry was covered on the inside with $10 \mathrm{~mm}$ lime render. Around mid-height of each wall mock-up was positioned a wooden beam of $17.5 \times 17.5 \mathrm{~cm}$ cross section, which extended about half a meter into the room of the container and $10 \mathrm{~cm}$ into the masonry. The beam rested on a horizontal, longitudinal $10 \times 10 \mathrm{~cm}$ wooden lath, which was inserted in a recess in the masonry. A $15 \mathrm{~mm}$ OSB board over and under the part of the beam that stretched into the room mimicked floor and ceiling in a floor separation, and it was partly filled with a $100 \mathrm{~mm}$ mineral wool batt. An indoor separation wall of half stone brick ( $10.8 \mathrm{~cm}$ plus $10 \mathrm{~mm}$ lime render on either side) was 
positioned in full wall height next to the wooden beam, see the picture in Fig. 9 (right). 2 x $12 \mathrm{~mm}$ gypsum board was used as interior cladding of the insulation. No vapour retarder or interior paint was used in the walls described in this paper. Each wall was instrumented with 9 HYT 221 sensors (from Innovative Sensor Technology, IST AG) that measured temperature and relative humidity with hourly intervals in two positions in the masonry, in the lime render, on the warm side of the insulation, at two positions in the wooden beam, and on the cold side of the wooden lath. A weather station measured the outdoor weather conditions and indoor temperature and relative humidity was logged with hourly intervals. A vertical cross-section through the set-up with indication of sensor positions is shown in Fig. 9 (left). Further description of the facility, its measuring system, and the other walls can be found in the PhD-thesis of Tommy Odgaard [2].

A wall, which was insulated on the interior side with the HygInsu system (of thickness $100 \mathrm{~mm}$ ) occupied one of the places facing north-east. The instrumented wall cavity that was insulated with the HygInsu system was positioned over beam height and had width $530 \mathrm{~mm}$ and height $952 \mathrm{~mm}$. The HygInsu sample fit tight to the sides of the cavity.

Along the same façade were also two walls, which were insulated with calcium silicate $(100 \mathrm{~mm})$ and iQTherm $(80 \mathrm{~mm})$, respectively. The iQ-Therm and calcium silicate insulation systems used a dedicated glue mortar to adhere the insulation to the lime render, and these two walls did not have gypsum boards as interior cladding.

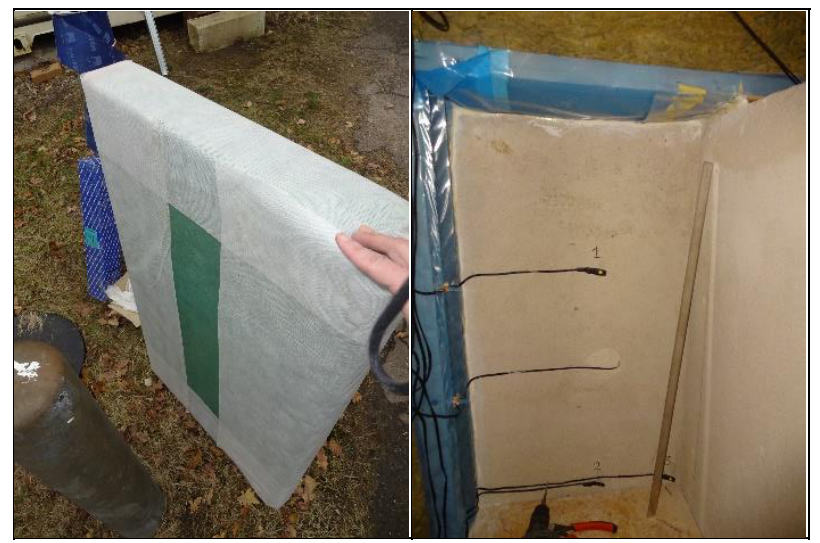

Fig. 10. Left: Insulation batt with HygInsu system before installation. Right: Place reserved for HygInsu system behind interior rendering of the masonry with sensors to measure humidity at the wick/render interface.

\subsection{Experimental conditions}

The interior of the container was heated with electric heaters to around $20^{\circ} \mathrm{C}$, and a humidifier kept the humidity at the relatively high level of around $60 \% \mathrm{RH}$ year round (although the humidifier was off for a few months in the winter 2018/19). Fans stirred the air so the interior conditions were well mixed. A picture of the containers with their masonry wall is shown in Fig. 8. The interior insulation system with HygInsu was mounted in November 2016, whereas the walls with calcium silicate and iQ-Therm had been installed and in operation since May 2015. Fig. 10 shows a picture of an insulation batt of stone wool outfitted with the HygInsu system. In addition to the HYT sensor, which measures temperature and RH within the wall rendering, three HYT sensors in different lateral and vertical positions close to the centre and perimeter of the insulation batt measured temperature and $\mathrm{RH}$ at the interface between the HygInsu system's Hygrowick glass fibre felt at the cold, outer side of the insulation. Like in other walls, a HYT sensor measured temperature and $\mathrm{RH}$ in the interface between interior gypsum cladding and the insulation system close to the centre of the insulation.

\subsection{Results}

The results are illustrated by means of the measured relative humidity in some of the positions, which are deemed to be most interesting and also most likely influenced by the performance of the insulation system. These are:

- Measuring position 3, in lime render on the inside of the masonry/outside of the insulation system and its glue mortar. Three extra measurement positions for HygInsu at the interface between wick and render (Fig. 11).

- Measuring position 4, in interface between interior gypsum cladding and inside surface of insulation (Fig. 12)

- Measuring position 5, at the cold, exterior side of the wooden lath (Fig. 13)

- Measuring position 6, in wooden beam end (Fig. 14).

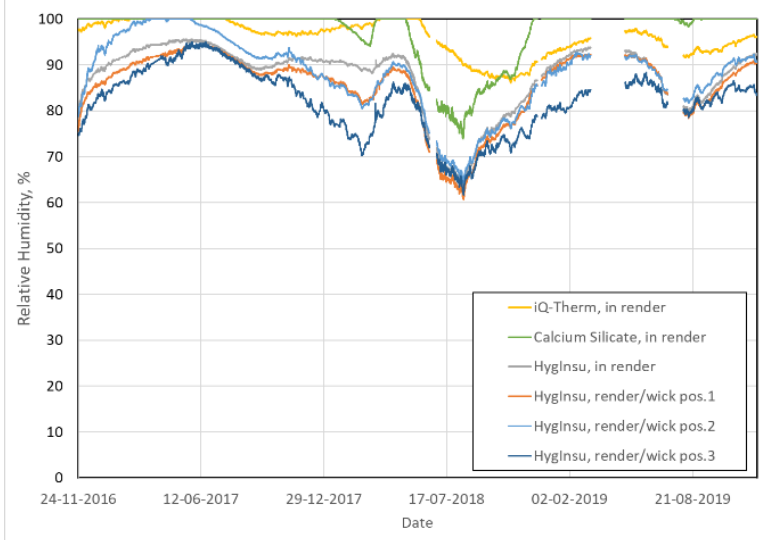

Fig. 11. Relative humidity in lime render on the inside of the masonry, and for HygInsu in the positions of the wick/render interface (measuring position 3).

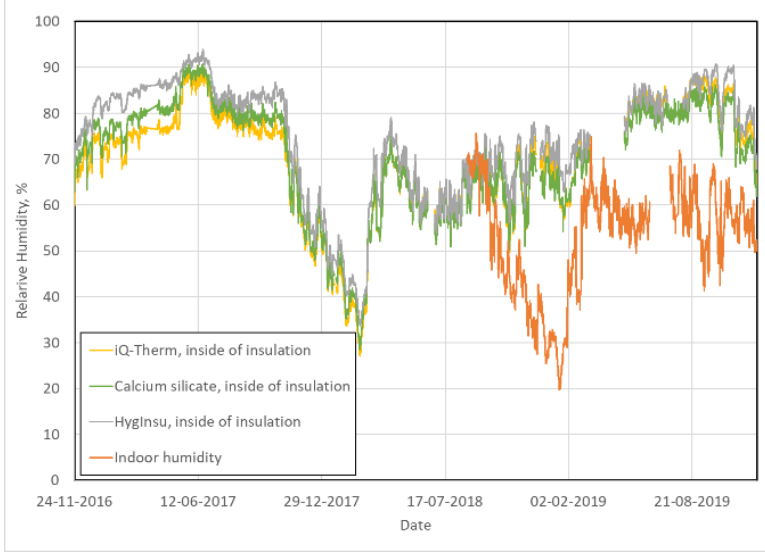


Fig. 12. Relative humidity in the indoor environment, and at interface between interior cladding and inside surface of insulation (measuring position 4 ).

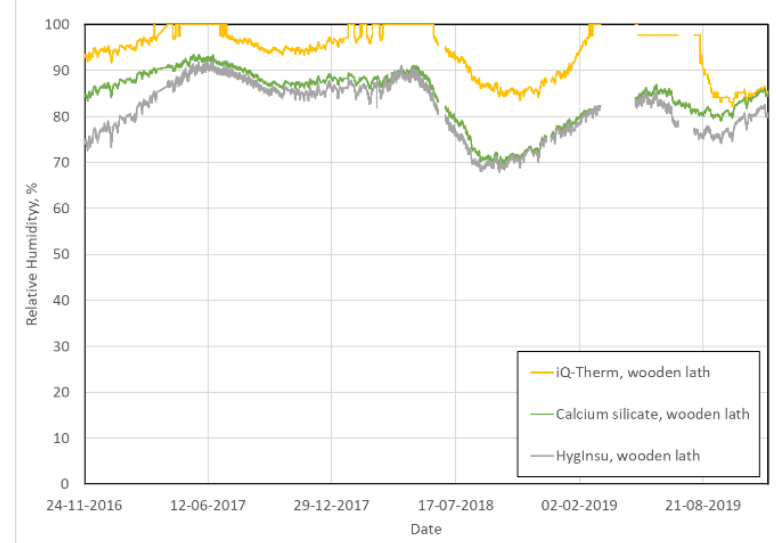

Fig. 13. Relative humidity at cold, exterior side of wooden lath (measuring position 5).

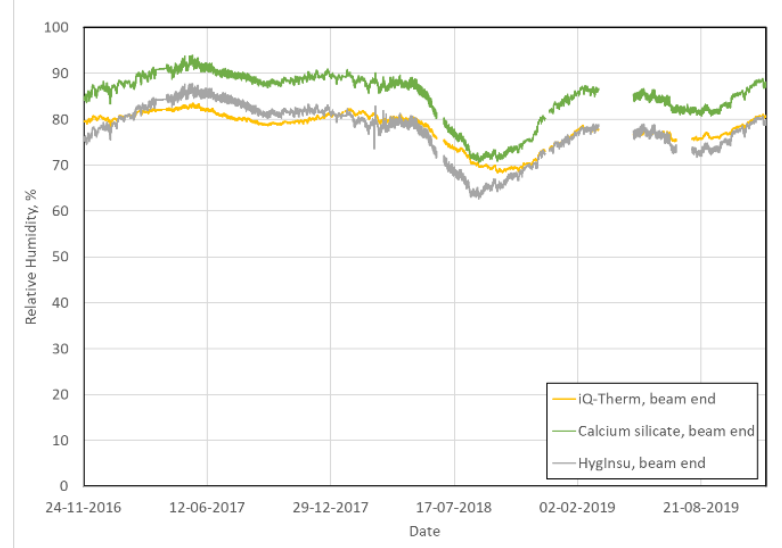

Fig. 14. Relative humidity in wooden beam end (measuring position 6).

\section{Discussion and Conclusion}

The paper has demonstrated some initial experiments of laboratory and outdoor field test performance of prototypes of a new thermal insulation composite, named HygInsu, which is comprised of mineral wool convoluted in a capillary active fabric of glass fibre felt. The capillary active glass fibre felt makes it possible to remove the high moisture content that may usually occur in the critical interface between insulation and the inside of a solid brick wall. The new system has been tested side by side with commercial products of calcium silicate and a polyurethane product with capillary active calcium silicate channels (iQ-Therm). The experiments have shown, both in the laboratory tests that lasted almost four months and in the three-year field study, that the commercial systems may have critically high moisture levels.

In the case of laboratory tests with calcium silicate, the moisture content was steadily increasing for a couple of months and then reached a situation with steady high moisture content. Relative humidity reached saturation $(100 \% \mathrm{RH})$ for the coldest half of the material.
iQ-Therm performed better in the laboratory tests with only slow changes of moisture content and relative humidity, and tendencies that could go both up and down in moisture content during the measurement period. $\mathrm{RH}$ was around $90 \%$ on the cold side.

HygInsu demonstrated a very good capability in the laboratory tests to drain surplus moisture from the assembly, and the relative humidity measured in the material tended to be a little lower than what was measured for iQ-Therm, with RH topping at around 85\% among the measured positions. The system demonstrated at two occasions in the laboratory test that it was able within a month to drain surplus moisture that was added to the assembly. Thus, the system may have some resiliency to dry out moisture that in a practical situation has inadvertently entered the construction.

In the field tests, only relative humidity was measured as an indicator for moisture, but this was done in several positions in the tested brick walls with interior insulation. At the render on the cold side of the insulation system, the relative humidity was critically high for calcium silicate and iQ-Therm with values mostly above $90 \%$ or at saturation for calcium silicate, and around or above $90 \%$ for iQ-Therm. Among the wooden members, the wooden lath had critical relative humidity with the iQ-Therm system as RH was mostly above $90 \%$. The beam end performed better with RH around $80 \%$ or lower.

With calcium silicate, both the wooden lath and the beam end had RH mostly between 80 and $90 \%$, which can be assessed as a high, but perhaps not critical level.

A short summary of the humidity conditions seen in the field test with the HygInsu system is that the humidity was mostly at the same or slightly lower levels than what was seen in walls with the two other insulation systems. Particularly at the render outside of the insulation, there was a tendency for the relative humidity to be some $10 \%$ RH lower with HygInsu than with the two other systems.

A future study should use the measured data together with a recognized mould growth model to analyse the risk of fungal activity on the measured positions.

Altogether, while it has been sad to see some rather high humidity values in many of the performed tests, it has been encouraging to see the equal or somewhat better performance of the new insulation principle with HygInsu. However, it must be stated that these have been only some first tests of prototypical examples of the system, and more testing and assessment shall be needed.

\section{References}

1. RIBuild, Robust Internal Thermal Insulation of Historic Buildings, www.ribuild.eu/ (2020)

2. T. Odgaard, Challenges when retrofitting multi-storey buildings consisting of solid masonry facades and embedded wood with interior thermal insulation. $\mathrm{PhD}$ thesis, Technical University of Denmark (2019)

3. iQ-Therm, www.remmers.com (2020)

4. V. Koverdynsky, V. Korsgaard and C. Rode. The Wick-Concept for Thermal Insulation of Cold Piping. J. Bldg. Phys. 29, 313-327. (2006) 
5. Isover. Climcover. https://www.isover.dk/products/ climcover-lamella-hygrowick-hygrowicklamelmaatter. (2020)

6. N.K. Friis, C. Pedersen, Environmental impact and moisture transporting properties of materials used as internal extra insulation. Bachelor thesis, Technical University of Denmark (2016) 